\title{
Middle Temporal Gyrus
}

National Cancer Institute

\section{Source}

National Cancer Institute. Middle Temporal Gyrus. NCI Thesaurus. Code C33125.

A gyrus or ridge on the outer surface of the temporal lobe between the superior and middle temporal sulci. 